\title{
CRYSTAL CHEMISTRY AND ELECTRON LOCALIZATION IN Sn-DOPED $\mathrm{Fe}_{3} \mathrm{O}_{4}^{+}$
}

B. J. Evans, Lu San Pan and R. H. Voge1, Department of Chemistry, University of Michigan, Ann Arbor, Michigan 48104

\section{ABSTRACT}

For $\mathrm{Fe}_{3-\mathrm{x}} \mathrm{Sn}_{\mathrm{x}} \mathrm{O}_{4}$ at $300 \mathrm{~K}$ and $\mathrm{x}>0.1$, a paramagnetic quadrupole doublet pattern, in addition to the usual two magnetic patterns, is observed in the ${ }^{57} \mathrm{Fe}$ NGR spectra. This doublet is due to $\mathrm{A}$ site $\mathrm{Fe}^{2+}$ whose concentration for $0.1 \leq \mathrm{x} \leq 0.5$ is such that approximately equal amounts of $\mathrm{Fe}^{2+}$ and $\mathrm{Fe}^{3+}$ are on the $B$ site. The $200 \mathrm{kG}$ field at the $\mathrm{Sn}^{4+}$ site at $300 \mathrm{~K}$ is smaller than that in $\mathrm{NiFe}_{2} \mathrm{O}_{4}$. At $80 \mathrm{~K}$ a paramagnetic quadrupole doublet is observed in the ${ }^{119}$ Sn NGR spectrum and is due to $\mathrm{Sn}^{2+}$.

\section{INTRODUCTION}

Most nuclear gamma ray resonance (NGR) studies of doped $\mathrm{Fe}_{3} \mathrm{O}_{4}$ have been concerned with materials for which there is a decrease in the $\mathrm{Fe}^{2+}$ content. 1 We have, therefore, synthesized $\mathrm{Sn}$-doped $\mathrm{Fe}_{3} \mathrm{O}_{4}, \mathrm{Fe}_{3-\mathrm{x}} \mathrm{Sn}_{\mathrm{x}} \mathrm{O}_{4}$ for which $\mathrm{Fe}^{2+}$ increases with increasing $x$ and obtained their ${ }^{57} \mathrm{Fe}$ and ${ }^{119} \mathrm{Sn}$ NGR spectra at $300 \mathrm{~K}$ and $80 \mathrm{~K}$. Questions of particular interests are: (1) effect of a $\mathrm{Fe}^{2+} \mathrm{Fe}^{3+}$ ratio $>1$ on the conduction mechanism and the role of $\mathrm{Sn}^{4+}$, (2) confirmation of A site $\mathrm{Fe}^{2+}$, hereafter noted as $\mathrm{Fe}^{2+}(\mathrm{A})$, for $\mathrm{x}<0.5$, and (3) perturbation by $\mathrm{Sn}$ of the electron localization at the Verwey transition.

\section{EXPERIMENTAL}

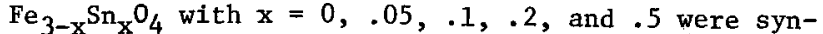
thesized by firing mixtures of spectroscopic grade $\mathrm{Fe}_{2} \mathrm{O}_{3}, \mathrm{Fe}$, and ${ }^{119} \mathrm{Sn}$ enriched $\mathrm{SnO}_{2}$ in evacuated and sealed silica tubes at $1273 \mathrm{~K}$. X-Ray diffraction analysis with a Guinier focusing camera showed the samples to be single phase and with lattice parameters for $x=0,0.05,0.1$, and 0.2 of $0.8395 \mathrm{~nm}, 0.8411 \mathrm{~nm}$, $0.8241 \mathrm{~nm}$, and $0.8453 \mathrm{~nm}$, respectively, in good agreement with earlier measurements.

Standard transmission NGR techniques and leastsquares curve fitting techniques were employed. 25 $\mathrm{mCi}{ }^{57} \mathrm{Co} / \mathrm{Rh}$ and $0.5 \mathrm{mCi}{ }^{119} \mathrm{Sn} / \mathrm{CaSnO}_{3}$ sources were used and were always at the same temperature as the absorber. The lines were assumed to be lorentzian for both nuclei and the $-1 / 2 \rightarrow-1 / 2$ transition was used to obtain the relative occupancies of the $A$ and $B$ sites by Fe since the corresponding lines were the most well resolved.

Table I

${ }^{57}$ Fe NGR Parameters of $\mathrm{Fe}_{3-\mathrm{x}} \mathrm{Sn}_{\times 4} \mathrm{O}_{4}$ at $300 \mathrm{~K}$

\begin{tabular}{|c|c|c|c|c|}
\hline$x$ & Pattern & $\begin{array}{l}\mathrm{H}_{\text {eff }} \\
(\mathrm{kG})\end{array}$ & $\begin{array}{l}\left.{ }_{(\mathrm{mm}} \mathrm{s}^{-1}\right)^{-I S} I \\
\text { I }\end{array}$ & $\begin{array}{l}\text { Area Ratio } \\
\text { II/I }\end{array}$ \\
\hline 0 & I & $\begin{array}{l}493 \\
463\end{array}$ & 0.40 & 1.80 \\
\hline 0.05 & $\begin{array}{l}\text { I } \\
\text { II }\end{array}$ & $\begin{array}{l}399 \\
379\end{array}$ & 0.36 & 2.20 \\
\hline 0.1 & $\begin{array}{l}\text { I } \\
\text { II }\end{array}$ & $\begin{array}{l}400 \\
375\end{array}$ & 0.31 & 2.04 \\
\hline 0.2 & $\begin{array}{l}\text { I } \\
\text { II }\end{array}$ & $\begin{array}{l}395 \\
366\end{array}$ & 0.32 & 2.8 \\
\hline 0.5 & $\begin{array}{l}\text { I } \\
\text { II }\end{array}$ & $\begin{array}{l}389 \\
358\end{array}$ & 0.33 & 3.2 \\
\hline
\end{tabular}

FE2.95 SN.05 04 IRON SPECTRA AT 302K

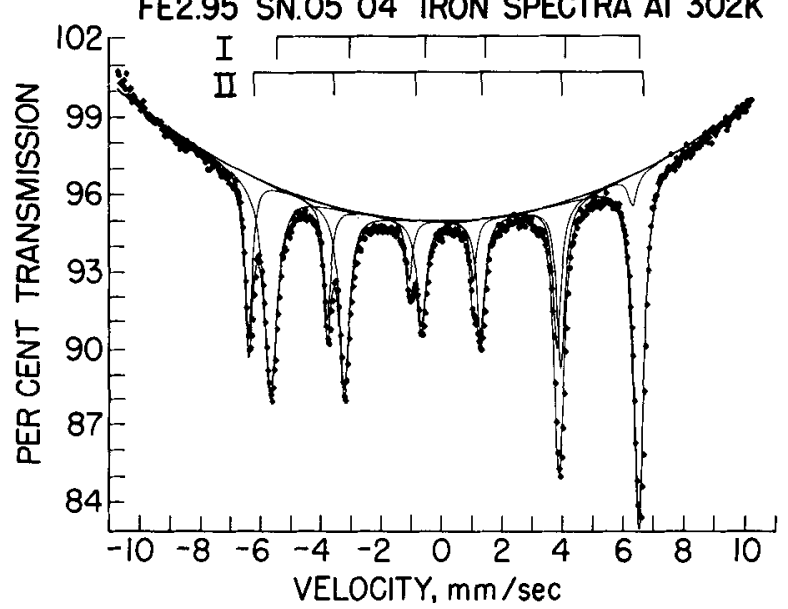

FE2.9 SN.I 04 IRON SPECTRA AT 302K

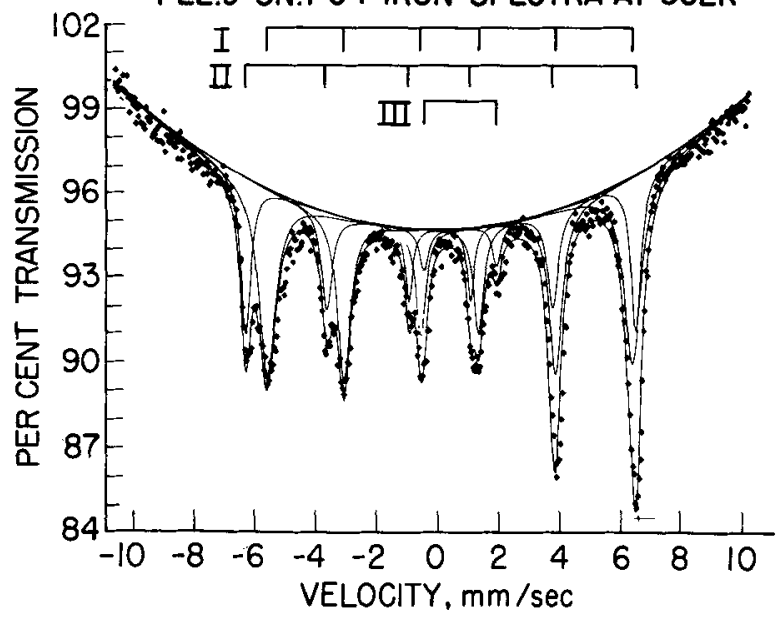

Fig. 1. ${ }^{57} \mathrm{Fe}$ NGR spectra of $\mathrm{Fe}_{3-\mathrm{x}} \mathrm{Sn}_{\mathrm{x}} \mathrm{O}_{4}, \mathrm{x}=0.05$, and 0.1 , at 302 K. Pattern III for $x=0.1$ is to be noted. RESULTS

$57 \mathrm{Fe}$ spectra at $300 \mathrm{~K}$ for $\mathrm{x}=0.05$ and 0,01 are given in Fig. 1 and those for ${ }^{119} \mathrm{Sn}$ at $300 \mathrm{~K}$ and $80 \mathrm{~K}$ for $x=0,1$ are given in Fig. 2, In order to account for the $57 \mathrm{Fe}$ spectra for $\mathrm{x}>0,1$, it is necessary to Introduce a quadrupole doublet (Pattern III) with an isomer shift, $\delta$, of $0.83 \mathrm{~mm} \mathrm{~s}^{-1}$ w.r.t. Fe and a quadrupole splitting, $\Delta E_{O}$, of $2.35 \mathrm{~mm} \mathrm{~s} \mathrm{~s}^{-1}$. The NGR parameters of patterns $I$ and II (cf, Fig. 1) for all samples are given in Table $I$. The III/I area ratio is 0.12 for $x=0.1$ and 0.37 for $x=0.2$. An accurate fit of pattern III for $x=0.5$ has not been possible. The Verwey transition has been determined using 57 Fe NGR and is above $100 \mathrm{~K}$ and rather sharp for $\mathrm{x}=0.05$. For $x>0.05$, the transition commences above $120 \mathrm{~K}$ and is smeared over a temperature interval of at least $40 \mathrm{~K}$. The ${ }^{119}$ Sn NGR parameters of the magnetic hyperfine pattern at $300 \mathrm{~K}$ and $80 \mathrm{~K}$ for $\mathrm{x}<0.5$ are given in Table II. The absorption line at $0 \mathrm{~mm} \mathrm{~s} \mathrm{~s}^{-1}$ is believed to be due to a $\mathrm{SnO}_{2}$ impurity undetected in the $\mathrm{X}$-ray diffraction analysis. For $x>0.05$, a quadrupole doublet (Pattern II of Fig. 2) appears in the $80 \mathrm{~K}$ spectra and is to be associated with the low temperature phase of $\mathrm{Fe}_{3} \mathrm{O}_{4}$. This pattern has a $\delta$ of $3.0 \mathrm{~mm} \mathrm{~s}^{-1}$ w.r.t. $\mathrm{CaSnO}_{3}$ and a $\Delta \mathrm{E}_{Q}$ of $2.06 \mathrm{~mm} \mathrm{~s} \mathrm{~s}^{-1}$ and is, therefore, characteristic of $\mathrm{Sn}^{2}+$. The II/I area ratio is 0.06 and 0.25 for $x=0.1$ and 0.2 , respectively. 
FE2.9 SN.1 04 TIN SPECTRA AT 302K

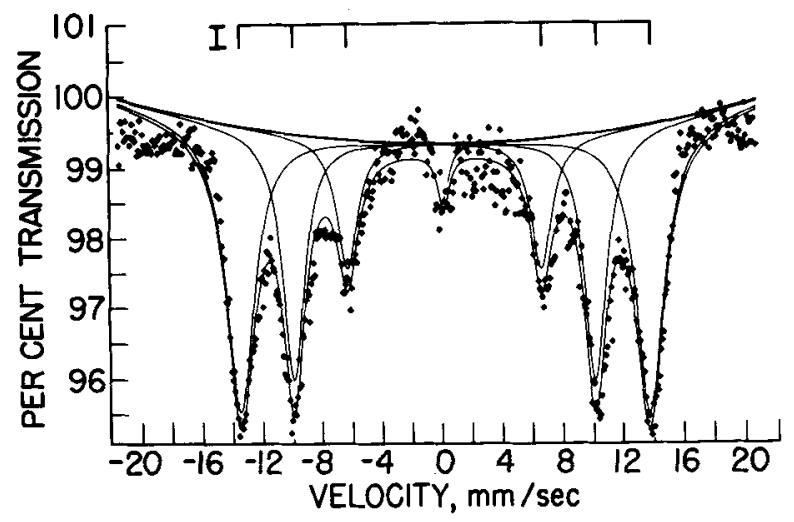

FE2.9 SN.1 04 TIN SPECTRA AT 77K

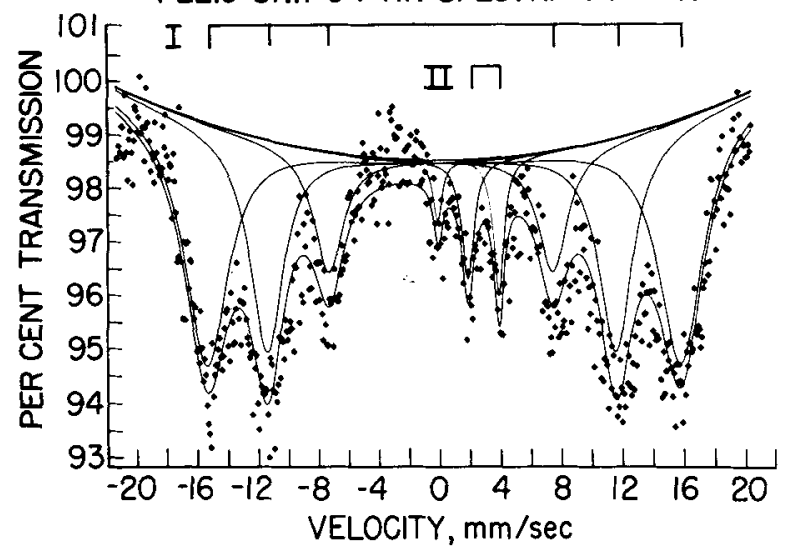

Fig. 2. ${ }^{119} \mathrm{Sn}$ NGR spectrum of $\mathrm{Fe}_{2.9} \mathrm{Sn}_{0.1} \mathrm{O}_{4}$ at $302 \mathrm{~K}$ and $77 \mathrm{~K}$ (below the Verwey transition). The paramagnetic pattern II and its large isomer shift in the $77 \mathrm{~K}$ spectrua is to be noted.

\section{Table II}

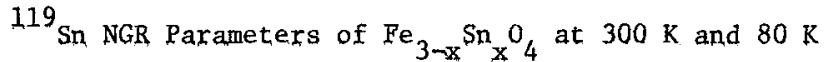

\begin{tabular}{|l|c|c|c|c|}
\hline $\mathrm{x}$ & $\begin{array}{c}\mathrm{H}_{\text {eff }} \\
\text { at 300 K } \\
(\mathrm{kG})\end{array}$ & $\begin{array}{c}\mathrm{H}_{\text {eff }} \\
\text { at } 80 \mathrm{~K} \\
(\mathrm{kG})\end{array}$ & $\begin{array}{c}\text { Isomer shift } \\
\text { at } 80 \mathrm{~K} \\
\left(\operatorname{mos} \mathrm{s}^{-1}\right)\end{array}$ & $\begin{array}{c}\text { Area Ratio } \\
\mathrm{II} / \mathrm{I}\end{array}$ \\
\hline 0.05 & 195 & 243 & +0.14 & - \\
0.1 & 197 & 229 & +0.17 & 0.06 \\
0.2 & 184 & 232 & +0.22 & 0.25 \\
\hline
\end{tabular}

DISCUSSION

The significant findings of this study are: the large II/I apparently (A site)/(B site), area ratios of the $57 \mathrm{Fe}$ spectrum, (2) the presence of paramagnetic $\mathrm{Fe}^{2+}$ at $300 \mathrm{~K}$, and (3) the existence of $\mathrm{Sn}^{2+}$ in the low-temperature phase. If all the A and B site cations contributed to patterns $I$ and II, respectively, the II/I area ratio should decrease with increasing $x$ since $\mathrm{Sn}^{4+}$ occupy the $\mathrm{B}$ site; ${ }^{2}$ this is not the case. The increase in the II/I area ratio with $x$ is due to the partial occupation of the $\mathrm{A}$ site by $\mathrm{Fe}^{2+}$, with the fractional occupation increasing with increasing $x^{2}$ and to the fact that these $\mathrm{Fe}^{2+}(\mathrm{A})$ ions contribute to neither pattern I nor II. The $\mathrm{Fe}^{2+}(\mathrm{A})$ gives rise to pattern III. If it is assumed that all $\mathrm{Fe}^{2+}(\mathrm{A})$ ions contribute to pattern III, then good agreement is obtained between the II/I area ratio and the fraction of $\mathrm{A}$ sites occupied by $\mathrm{Fe}^{2+}$ for $\mathrm{x}=0.1$ and 0.2 . The cation distributions for these two cases are $\left(\mathrm{Fe}^{2+} \cdot 88^{\mathrm{Fe}^{2+}} \cdot 12\right)\left[\mathrm{Fe}^{3+} \cdot 92^{\mathrm{Fe}^{2+}} \cdot 98^{\mathrm{Sn}} .1\right]$ and $\left(\mathrm{Fe}^{3+} .63^{\mathrm{Fe}^{2+}} .37^{2}\right)\left[\mathrm{Fe}^{3+} .97^{\mathrm{Fe}^{2+}} .83^{\mathrm{Sn}} .2\right]$. For $\mathrm{x}=0.5$,
1) the cation distribution determined from the II/I area ratio is $\left(\mathrm{Fe}^{3+}, 3^{\mathrm{Fe}^{2+}}, 7^{2}\right)\left[\mathrm{Fe}^{3+}, 8^{\mathrm{Fe}^{2+}}, 7^{\mathrm{Sn}}, 5^{3}\right.$, The ret markable feature of these results is the apparent adjustment in the $\mathrm{A}$ site $\mathrm{Fe}^{2+}$ conceptration to give approximately equal amounts of $\mathrm{Fe}^{2+}$ and $\mathrm{Fe}^{3+}$ on the octahedral site. A similar phenomenon was observed in $\mathrm{Fe}_{3-\mathrm{x}} \mathrm{Cr}_{\mathrm{x}_{4}} \mathrm{O}^{3}$ The paramagnetic character of $\mathrm{Fe}^{2+}(\mathrm{A})$ is due perhaps to clustering of $\mathrm{B}$ site $\mathrm{Sn}^{4+}$ ions about such $A$ site tons,

The magnetic ${ }^{119} \mathrm{Sn}$ pattern exhibits somewhat larger linewidths and hyperfine fields at $80 \mathrm{~K}$ than at $300 \mathrm{~K}$. The larger fields are due simply to the increase in the magnetization but the larger linewidths may be due to the lower symetry of the low-temperature phase, as expected. The quadrupole doublet due to $\mathrm{Sn}^{2+}$ is unexpected and suggests that the conduction electrons are localized on the Sn sites below the Verwey transition. Further support for this suggestion is found in the increase in the intensity of the $\mathrm{Sn}^{2+}$ pattern with increasing $x$.

While the $57 \mathrm{Fe}$ area ratio results are suggestive of pair-wise hopping at $300 \mathrm{~K}$, the localization of electrons on the $\mathrm{Sn}^{4+}$ sites at low temperatures is more readily explicable in terms of band conduction.

\section{REFERENCES}

+ Support of this study by the National Science Foundation, Grant GH-41419 is gratefully acknowledged.

1. B. J. Evans, AIP Conf. Proc. 24, 73 (1975) and references therein.

2. F. Basile, C. Djega-Mariadassou and P. Poix, J. Phys. Chem. Solids 35, 1067 (1974).

3. M. Robbins, G. K. Wertheim, R. C. Sherwood, and D. N. E. Buchanan, J. Phys. Chem. Solids $\underline{32}, 717$ (1971). 